\title{
Intermediate-term outcomes of aortic valve replacement with bioprosthetic or mechanical valves in patients on hemodialysis
}

\author{
Taro Nakatsu, MD, ${ }^{a}$ Kenji Minakata, MD, PhD, ${ }^{a}$ Shiro Tanaka, $\mathrm{PhD},{ }^{b}$ and Kenji Minatoya, MD, PhD, \\ PROGRESS-Kyoto Investigators*
}

\section{ABSTRACT}

Objective: To investigate the influence of choice of prosthesis (bioprosthetic valves or mechanical valves) on intermediate-term outcomes in patients on hemodialysis undergoing aortic valve replacement (AVR).

Methods: A multi-institutional retrospective cohort study was conducted in 18 Japanese centers. All adult patients on chronic hemodialysis who underwent AVR from 2008 and 2015 were included $(n=491)$. The early and late results were compared between groups. The hazard ratios were calculated using Cox regression and Fine-Gray models with adjustment for propensity score based on 41 confounders. The mean follow-up period was $2.5 \pm 2.1$ years (up to 8.3 years) with $98 \%$ completeness.

Results: There were 323 patients who received a bioprosthetic valve (group B), and 168 patients who received a mechanical valve (group $\mathrm{M}$ ). There was no significant difference for in-hospital death rate between groups (group B: $12.1 \%$; group M: $8.9 \% ; P=.29)$. The overall survival rate at 5 years after surgery was $39.3 \%$ in group $\mathrm{B}$ and $50.4 \%$ in group $\mathrm{M}(P=.42)$. Freedom from reoperation at 5 years was $97.1 \%$ in group $\mathrm{B}$ and $97.8 \%$ in group $\mathrm{M}(P=.88)$. On propensity-score adjusted analyses, there were no significant differences in overall survival between groups.

Conclusions: There were no significant differences in overall survival between bioprosthetic valves and mechanical valves in patients on hemodialysis undergoing AVR. (J Thorac Cardiovasc Surg 2019;157:2177-86)

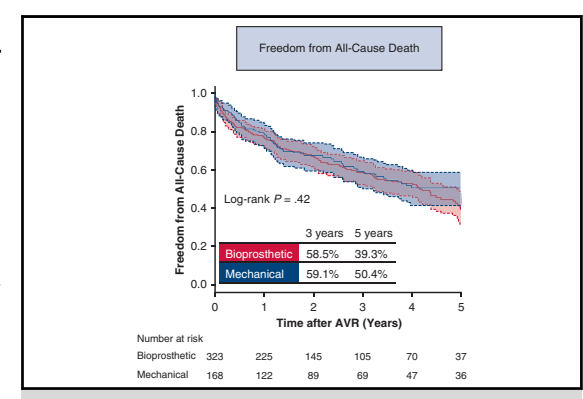

Survival curve in patients on dialysis undergoing AVR; bioprosthetic vs mechanical valves.

\section{Central Message}

There were no differences in overall and valverelated survival between biological and mechanical valves in patients on hemodialysis undergoing AVR.

\section{Perspective}

There were no significant differences in terms of overall survival between bioprosthetic valves and mechanical valves in patients on hemodialysis undergoing aortic valve replacement.

See Commentary on page 2187.
Although transcatheter aortic valve replacement (AVR) is becoming a vital option for patients at both high and intermediate risk for open surgery, ${ }^{1-3}$ surgical AVR still remains the gold standard in many patients with severe aortic valve stenosis. ${ }^{4}$ There is some debate regarding the best choice of prosthetic valve in patients on hemodialysis.

\footnotetext{
From the ${ }^{\mathrm{a} C a r d i o v a s c u l a r}$ Surgery, and ${ }^{\mathrm{b}}$ Clinical Biostatistics, Kyoto University Graduate School of Medicine, Kyoto, Japan.

This paper was originally presented at The American Association for Thoracic Surgery Centennial, Boston, Massachusetts, May 2, 2017.

*The PROGRESS-Kyoto investigators are listed in the Appendix.

Received for publication Nov 17, 2017; revisions received Aug 7, 2018; accepted for publication Aug 26, 2018; available ahead of print Oct 26, 2018

Address for reprints: Kenji Minatoya, MD, PhD, Department of Cardiovascular Surgery, Kyoto University Graduate School of Medicine, 54 Shogoin Kawaharacho, Sakyo-ku, Kyoto city, 606-8507, Japan (E-mail: minatoya@kuhp.kyoto-u.ac.jp). $0022-5223 / \$ 36.00$

Copyright (c) 2019 by The American Association for Thoracic Surgery https://doi.org/10.1016/j.jtcvs.2018.08.104
}

The decisions should be made based on the risks of long-term anticoagulation associated with mechanical valves and the possible need for reoperation due to structural valve deterioration (SVD) in bioprosthetic valves. The predicted life expectancy of patients with end-stage renal disease also must be considered.

The American College of Cardiology/American Heart Association treatment guidelines published in 1998 recommended mechanical valves for patients on hemodialysis because it had been reported that bioprosthetic valves in such patients tended to develop SVD in the early

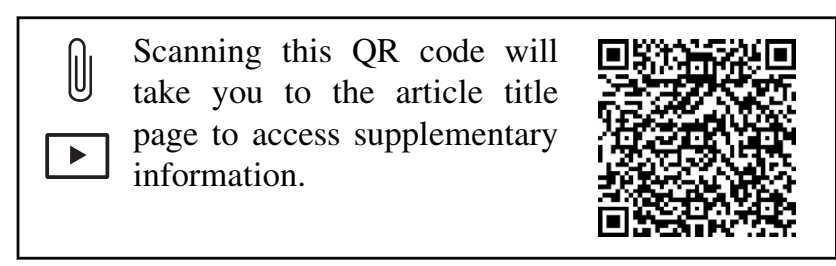




\section{Abbreviations and Acronyms \\ AVR = aortic valve replacement \\ $\mathrm{CABG}=$ coronary artery bypass grafting \\ $\mathrm{HR}=$ hazard ratio \\ PT-INR $=$ prothrombin time-international normalized ratio \\ PVE = prosthetic valve endocarditis \\ SVD = structural valve deterioration}

postoperative period..$^{5-7}$ However, other studies found that patients on hemodialysis undergoing AVR have limited life expectancy and their bioprosthetic valves did not survive long enough to experience significant SVD requiring reoperation. ${ }^{8-14}$ Accordingly, the recommendation of mechanical valves in patients on hemodialysis was removed from the revised American College of Cardiology/American Heart Association guidelines in 2006. ${ }^{15}$ Since then, the guidelines have never addressed any specific considerations on choice of prosthetic valves for patients on hemodialysis. ${ }^{4,16}$

Although mechanical valves remain a suitable choice for patients on hemodialysis, especially younger ones who wish to avoid reoperation, there has been a significant trend toward bioprosthetic valves, even in younger patients. ${ }^{17}$ This trend is based on the desire to reduce the risk of bleeding complications, which may be accelerated by chronic hemodialysis. However, there are no robust data regarding the durability of bioprosthetic valves and the risk of major bleeding for mechanical valves in patients on hemodialysis. The aim of this study was to assess the intermediate-term outcomes for patients on hemodialysis undergoing AVR with either bioprosthetic valves or mechanical valves.

\section{SUBJECTS AND METHODS \\ Subjects and Data Collection}

We organized a multicenter retrospective observational study group in 18 Japanese centers, which we called the PROGRESS-Kyoto (PROsthetic selection for patients with end-staGe REnal diSeaSe in Kyoto). Subjects were 491 consecutive patients who underwent AVR using either bioprosthetic valves or mechanical valves between January 2008 and December 2015 who were on chronic hemodialysis (for more than 1 month) at the time of surgery (Figure E1). Subjects included those who underwent concomitant procedures such as coronary artery bypass grafting (CABG), mitral and/or tricuspid valve procedures, and thoracic aortic aneurysm repair procedures including aortic root replacement using composite grafts. Also, redo sternotomy was included. One of the reasons we included these patients undergoing various concomitant procedures was that many of dialysis-dependent patients who require AVR have other morbid conditions such as coronary artery disease caused by an extension of systemic manifestation as a result of end-stage renal disease. Patient characteristics and surgical information were obtained from medical records at each study center according to prespecified criteria. In addition, all the subjects who survived the surgery underwent follow-up surveys. Late outcomes were determined from medical records whenever available or from written correspondence with patients' primary physicians and/or nephrologists, or direct patient contact via mailed questionnaires or telephone interviews when necessary. Clinical data, including serial echocardiographic studies during the follow-up period, were collected by contacting referring physicians or nephrologists. This study was approved by the institutional review board of the Medical Ethics Committee of the Kyoto University Graduate School of Medicine (R 0348; date of approval: January 4, 2016), as well as those of all the participating centers. All patients and their family gave informed consent.

\section{Definitions of Events}

Definitions of each event were based on the Society of Thoracic Surgeons guidelines for reporting mortality or morbidity after cardiac valve interventions, published in $2008 .{ }^{18}$ In short, the term SVD refers to changes intrinsic to the valve, such as wear, fracture, poppet escape, calcification, leaflet tear, stent creep, and suture line disruption of components of a prosthetic valve. In addition, we defined SVD as the presence of moderate or greater transvalvular regurgitation, or aortic valve peak velocity $\geq 4 \mathrm{~m} / \mathrm{s}$ with a progression of $\geq 1 \mathrm{~m} / \mathrm{s}$ detected by Doppler echocardiography from the immediate postoperative study to the most recent study. Valve-related death was defined as any death caused by SVD, nonstructural dysfunction, valve thrombosis, embolism, bleeding event, or operated valve endocarditis; death related to reintervention on the prosthetic valve; or sudden, unexplained death. Deaths caused by heart failure in patients with advanced myocardial disease and satisfactorily functioning cardiac valves were not counted. In-hospital mortality was defined as death occurring within 30 days of surgery or at any time during the index hospitalization.

\section{Statistical Analysis}

All continuous variables were expressed as means \pm standard deviation. Categorical variables are described as frequencies and proportions compared with Fisher exact tests or $\chi^{2}$ test. Postoperative overall survival, freedom from valve-related death, bleeding-related death, bleeding events, thromboembolic events, prosthetic valve endocarditis (PVE), and reoperation due to SVD or nonstructural dysfunction were estimated by the Kaplan-Meier method. The associations between prosthetic valve selection and survival and other events were assessed with log-rank tests. In these analyses, only the first occurrence of a nonfatal event was counted. In addition, an unadjusted analysis was performed stratified by age at operation (younger than 70 years of age vs 70 years or older) for overall survival and freedom from reoperation. In addition, because the patients' backgrounds as well as operative variables were different between the 2 groups, we conducted a propensity score analysis to adjust for 41 variables: age, sex, body mass index, body surface area, CHADS2 score, duration of dialysis, cause of dialysis, diabetes mellitus, use of insulin, hypertension, dyslipidemia, infective endocarditis, active infective endocarditis, chronic obstructive pulmonary disease, peripheral artery disease, history of cerebral vascular disease, history of cardiac operation (redo operation), acute myocardial infarction, New York Heart Association functional class, preoperative shock, preoperative ejection fraction, grade of aortic valve regurgitation, grade of aortic stenosis, peak velocity across aortic valve, grade of mitral valve regurgitation, grade of tricuspid valve regurgitation, emergency surgery, operation time, cardiopulmonary bypass time, aortic crossclamp time, usage of intra-aortic balloon pumping, CABG, number of grafts on $\mathrm{CABG}$, prosthetic aortic valve size, concomitant mitral valve surgery, concomitant tricuspid valve surgery, concomitant thoracic aortic surgery, acute aortic dissection, concomitant aortic root surgery, concomitant arrhythmia correcting surgery, and date of operation.

Hazard ratios (HRs) were calculated using Cox regression model with adjustment for propensity score with a bioprosthetic valve as a reference, ie, HR more than 1 indicates that a bioprosthetic valve is superior, whereas less than 1 indicates that a mechanical valve is superior. We also conducted 
the same analysis in patients undergoing first-time, isolated AVR $(\mathrm{n}=183)$. In addition, the same analyses were conducted to compare the subgroups according to the age at operation (younger than 70 years of age vs 70 years or older) and the HRs from each subgroup were compared with the use of interaction tests of the propensity score adjusted Cox regression models. In addition, we performed 2 sensitivity analyses: Fine-Gray models that accounted for death as a competing risk for other late events, and inverse-probability weighted Cox regression using weights calculated from the propensity score. All $P$ values are 2 -sided, and a $P$ value $<.05$ was considered statistically significant. An academic statistician (S.T.) conducted all analyses using SAS software, version 9.4 (SAS Institute, Cary, NC).

\section{RESULTS}

Among the 491 patients, 323 patients underwent AVR with bioprosthetic valves (group B), whereas 168 patients underwent AVR with mechanical valves (group M). The proportion of prosthetic valve choice in each study year is shown in Figure E2. There was a trend toward using bioprosthetic valves in the later series of the study, although mechanical valves remained the choice for a certain number of patients. The patients' baseline characteristics and operative variables in each group are shown in Table 1. The patients in group B were significantly older and had greater prevalence of diabetes mellitus and longer duration of dialysis before surgery than those in group M. With regard to the operative variables, there were no differences between groups in the prevalence of concomitant procedures, such as CABG or mitral/tricuspid valve procedures. However, the patients in group B had shorter cardiopulmonary bypass time and aortic crossclamp time than those in group $\mathrm{M}$. The mean size of prosthetic valves was slightly larger in group B than in group M. The early outcomes including causes of death are summarized in Table 2. There were no significant differences for in-hospital deaths $(12.1 \%$ in group $\mathrm{B}$, and $8.9 \%$ in group $\mathrm{M}, P=.36$ ). In terms of other perioperative complications, there were more perioperative myocardial infarctions in group $\mathrm{M}$, whereas postoperative atrial fibrillation was more common in group B. More importantly, gastrointestinal complications, including bowel ischemia and subsequent sepsis, were high in both groups. Also, infection rates were high, both of which seemed to contribute to high early mortalities.

The mean follow-up period was $2.5 \pm 2.1$ years $(2.3 \pm 2.0$ years in group B, $2.8 \pm 2.3$ years in group $\mathrm{M})$. The follow-up completeness was $98 \%$ at the time of the latest follow-up survey (as of December 31, 2016). Unadjusted survival estimates of both group B and group $\mathrm{M}$ are shown by Kaplan-Meier curves in Figure 1, A. Also, unadjusted survival estimates among the patients undergoing first time, isolated AVR are shown in Figure $1, B$. There were no significant differences in overall survival rates between the 2 groups (log-rank $P=.42$ and .13 , respectively). In Figure 2, $A$, unadjusted overall
TABLE 1. Patient characteristics and operative variables

\begin{tabular}{|c|c|c|c|}
\hline Characteristics & $\begin{array}{c}\text { Group B } \\
(\mathrm{n}=323), \\
\text { bioprosthetic }\end{array}$ & $\begin{array}{c}\text { Group M } \\
(n=168) \text {, } \\
\text { mechanical }\end{array}$ & $P$ value \\
\hline \multicolumn{4}{|l|}{ Preoperative variables } \\
\hline Age, y & $73.6 \pm 7.0$ & $64.8 \pm 9.1$ & $<.01$ \\
\hline Male sex & $206(63.8 \%)$ & $108(64.3 \%)$ & .92 \\
\hline Body mass index, $\mathrm{kg} / \mathrm{m}^{2}$ & $20.8 \pm 3.3$ & $21.2 \pm 3.9$ & .20 \\
\hline Body surface area, $\mathrm{m}^{2}$ & $1.50 \pm 0.16$ & $1.55 \pm 0.20$ & $<.01$ \\
\hline CHADS2 score & $2.9 \pm 1.3$ & $2.3 \pm 1.2$ & $<.01$ \\
\hline Dialysis history, y & $10.0 \pm 8.0$ & $12.2 \pm 8.0$ & $<.01$ \\
\hline Cause of dialysis & & & $<.01$ \\
\hline Diabetic & $110(34.1 \%)$ & $38(22.6 \%)$ & \\
\hline Nondiabetic & $213(65.9 \%)$ & $130(77.4 \%)$ & \\
\hline Diabetes mellitus & $128(39.6 \%)$ & $42(25.0 \%)$ & $<.01$ \\
\hline On insulin & $45(14.3 \%)$ & $20(12.0 \%)$ & .59 \\
\hline Hypertension & $98(30.3 \%)$ & $45(26.8 \%)$ & .47 \\
\hline Dyslipidemia & $260(80.5 \%)$ & $128(76.2 \%)$ & .32 \\
\hline Infective endocarditis & $18(5.6 \%)$ & $7(4.2 \%)$ & .67 \\
\hline $\begin{array}{l}\text { Active infective } \\
\text { endocarditis }\end{array}$ & $13(4.0 \%)$ & $4(2.4 \%)$ & .44 \\
\hline $\begin{array}{l}\text { Chronic obstructive } \\
\text { pulmonary disease }\end{array}$ & $47(14.7 \%)$ & $19(11.4 \%)$ & .41 \\
\hline Peripheral arterial disease & $106(34.8 \%)$ & $62(37.8 \%)$ & .51 \\
\hline Cerebrovascular disease & $77(23.8 \%)$ & $42(25.0 \%)$ & .86 \\
\hline Reoperation & $15(4.7 \%)$ & $15(8.9 \%)$ & .10 \\
\hline $\begin{array}{l}\text { Acute myocardial } \\
\text { infarction }\end{array}$ & $15(4.7 \%)$ & $5(3.0 \%)$ & .47 \\
\hline NYHA functional class & & & .08 \\
\hline I & $99(30.7)$ & $50(29.8 \%)$ & \\
\hline II & $114(35.3 \%)$ & $77(45.8 \%)$ & \\
\hline III & $81(25.1 \%)$ & $28(16.7 \%)$ & \\
\hline IV & $29(9.0 \%)$ & $13(7.7 \%)$ & \\
\hline Shock & $14(4.3 \%)$ & $4(2.4 \%)$ & .32 \\
\hline $\begin{array}{c}\text { Preoperative ejection } \\
\text { fraction, } \%\end{array}$ & & & .95 \\
\hline$\leq 30$ & $20(6.3 \%)$ & $11(6.7 \%)$ & \\
\hline $30-60$ & $159(49.7 \%)$ & $83(50.6 \%)$ & \\
\hline$>60$ & $141(44.1 \%)$ & $70(42.7 \%)$ & \\
\hline $\begin{array}{l}\text { Grade of aortic } \\
\text { regurgitation }\end{array}$ & & & .36 \\
\hline None & $61(18.9 \%)$ & $39(23.2 \%)$ & \\
\hline 1 & $114(35.4 \%)$ & $60(35.7 \%)$ & \\
\hline 2 & $96(29.8 \%)$ & $38(22.6 \%)$ & \\
\hline 3 & $33(10.2 \%)$ & $17(10.1 \%)$ & \\
\hline 4 & $18(5.6 \%)$ & $14(8.3 \%)$ & \\
\hline Aortic valve stenosis & $289(89.5 \%)$ & $149(88.7 \%)$ & .79 \\
\hline $\begin{array}{l}\text { Peak velocity across the } \\
\text { aortic valve }\end{array}$ & $4.0 \pm 1.0$ & $4.3 \pm 2.0$ & .08 \\
\hline $\begin{array}{l}\text { Grade of mitral } \\
\text { regurgitation }\end{array}$ & & & .21 \\
\hline None & $55(17.1 \%)$ & $40(24.1 \%)$ & \\
\hline 1 & $118(36.8 \%)$ & $55(33.1 \%)$ & \\
\hline 2 & $101(31.5 \%)$ & $44(26.5 \%)$ & \\
\hline 3 & $30(9.3 \%)$ & $21(12.7 \%)$ & \\
\hline 4 & $17(5.3 \%)$ & $6(3.6 \%)$ & \\
\hline
\end{tabular}


TABLE 1. Continued

\begin{tabular}{|c|c|c|c|}
\hline Characteristics & $\begin{array}{c}\text { Group B } \\
(\mathrm{n}=323), \\
\text { bioprosthetic }\end{array}$ & $\begin{array}{c}\text { Group M } \\
(n=168), \\
\text { mechanical }\end{array}$ & $P$ value \\
\hline $\begin{array}{c}\text { Grade of tricuspid } \\
\text { regurgitation }\end{array}$ & & & .37 \\
\hline None & $113(35.4 \%)$ & $73(43.5 \%)$ & \\
\hline 1 & $120(37.6 \%)$ & $55(32.7 \%)$ & \\
\hline 2 & $72(22.6 \%)$ & $30(17.9 \%)$ & \\
\hline 3 & $11(3.4 \%)$ & $8(4.8 \%)$ & \\
\hline 4 & $3(0.9 \%)$ & $2(1.2 \%)$ & \\
\hline \multicolumn{4}{|l|}{ Operative variables } \\
\hline Operation status & & & .62 \\
\hline Emergency & $10(3.1 \%)$ & $6(3.6 \%)$ & \\
\hline Urgent & $10(3.1 \%)$ & $8(4.8 \%)$ & \\
\hline Operation time, min & $354 \pm 136$ & $375 \pm 133$ & .11 \\
\hline $\begin{array}{l}\text { Cardiopulmonary bypass } \\
\text { time, min }\end{array}$ & $163 \pm 75$ & $192 \pm 74$ & $<.01$ \\
\hline $\begin{array}{l}\text { Aortic crossclamp time, } \\
\text { min }\end{array}$ & $109 \pm 52$ & $129 \pm 53$ & $<.01$ \\
\hline Intra-aortic balloon pump & $22(6.9 \%)$ & $13(7.7 \%)$ & .74 \\
\hline Aortic valve size, $\mathrm{mm}$ & $21.1 \pm 1.7$ & $20.5 \pm 2.1$ & $<.01$ \\
\hline $\begin{array}{l}\text { Isolated aortic valve } \\
\text { replacement }\end{array}$ & $126(39.1 \%)$ & $57(33.9 \%)$ & .30 \\
\hline $\begin{array}{l}\text { Coronary artery bypass } \\
\text { grafting }\end{array}$ & $122(37.8 \%)$ & $55(32.7 \%)$ & .28 \\
\hline Graft number/patient & $1.9 \pm 1.0$ & $1.7 \pm 0.9$ & .26 \\
\hline Mitral valve surgery & $64(19.9 \%)$ & $43(25.6 \%)$ & .17 \\
\hline Mitral annuloplasty & $24(7.5 \%)$ & $14(8.3 \%)$ & - \\
\hline Mitral valve repair & $15(4.7 \%)$ & $5(3.0 \%)$ & - \\
\hline Mitral valve replacement & $25(7.8 \%)$ & $24(14.3 \%)$ & .16 \\
\hline Tricuspid annuloplasty & $28(8.7 \%)$ & $17(10.1 \%)$ & .62 \\
\hline Aortic surgery & $14(4.3 \%)$ & $14(8.3 \%)$ & .1 \\
\hline Acute aortic dissection & $3(0.9 \%)$ & $4(2.4 \%)$ & .22 \\
\hline Aortic root operation & $1(0.3 \%)$ & $7(4.2 \%)$ & $<.01$ \\
\hline Rhythm-correcting surgery & $25(8.0 \%)$ & $11(6.6 \%)$ & .72 \\
\hline
\end{tabular}

CHADS2, Congestive heart failure, Hypertension, Age $>75$, Diabetes mellitus, and prior Stroke or transient ischemic attack score; NYHA, New York Heart Association.

survival rates stratified by age at operation (younger than 70 years of age vs 70 years or older) are shown. Of note, even in patients younger than 70 years of age, 5-year survival rates were $48.5 \%$ in group B and $59.6 \%$ in group M. As shown in Figure 2, $B$, there were no significant differences in freedom from valve-related death between groups (unadjusted, $\log$-rank $P=.17$ ). The late outcomes are summarized in Table 3. Of note, some patients experienced more than one bleeding event. Freedom from valve-related events is shown in Figure 3. As shown in Figure 3, A, freedom from bleeding events at 5 years was $75.0 \%$ in group $B$ and $70.0 \%$ in group $M$ (log-rank $P=.65)$. In contrast, freedom from thromboembolic events at 5 years was $92.9 \%$ in group B and $94.3 \%$ in group $M$ (log rank $P=.64$ ) (Figure 3,B). Also, there were no significant differences in reoperation rates between groups. Freedom from reoperation at 5 years was $97.1 \%$ in group B
TABLE 2. Early results

\begin{tabular}{|c|c|c|c|}
\hline & $\begin{array}{c}\text { Group B } \\
(\mathrm{n}=\mathbf{3 2 3}), \\
\text { bioprosthetic }\end{array}$ & $\begin{array}{c}\text { Group M } \\
(n=168), \\
\text { mechanical }\end{array}$ & $\begin{array}{c}P \\
\text { value }\end{array}$ \\
\hline In-hospital death & $39(12.1 \%)$ & $15(8.9 \%)$ & .36 \\
\hline Cardiac & 6 & 5 & \\
\hline Sepsis & 9 & 3 & \\
\hline Bowel ischemia & 13 & 4 & \\
\hline Pneumonia & 7 & 3 & \\
\hline Others & 4 & 0 & \\
\hline Reoperation for bleeding & $14(4.4 \%)$ & $8(4.8 \%)$ & .82 \\
\hline Cerebral infarction & $18(5.7 \%)$ & $15(9.1 \%)$ & .23 \\
\hline Transient ischemic attack & $20(6.3 \%)$ & $18(10.9 \%)$ & .11 \\
\hline $\begin{array}{l}\text { Perioperative myocardial } \\
\text { infarction }\end{array}$ & $3(0.9 \%)$ & $7(4.3 \%)$ & .04 \\
\hline Complete heart block & $20(7.2 \%)$ & $13(8.5 \%)$ & .77 \\
\hline Cardiac tamponade & $13(4.1 \%)$ & $4(2.4 \%)$ & .50 \\
\hline $\begin{array}{l}\text { Gastrointestinal } \\
\text { complications }\end{array}$ & $32(10.1 \%)$ & $19(11.5 \%)$ & .75 \\
\hline Multiorgan failure & $25(7.9 \%)$ & $12(7.3 \%)$ & .94 \\
\hline Atrial fibrillation & $118(37.5 \%)$ & $47(28.5 \%)$ & .06 \\
\hline Deep sternal wound infection & $11(3.5 \%)$ & $8(4.8 \%)$ & .47 \\
\hline Sepsis & $34(10.8 \%)$ & $20(12.1 \%)$ & .77 \\
\hline $\begin{array}{l}\text { Prolonged ventilation } \\
24-72 \mathrm{~h} \\
\geq 72 \mathrm{~h}\end{array}$ & $\begin{array}{l}35(11.1 \%) \\
42(13.3 \%)\end{array}$ & $\begin{array}{l}18(10.9 \%) \\
34(20.6 \%)\end{array}$ & .11 \\
\hline Pneumonia & $49(15.5 \%)$ & $17(10.3 \%)$ & .15 \\
\hline
\end{tabular}

and $97.8 \%$ in group $\mathrm{M}(\log$-rank $P=.88)$ (Figure $4, A)$. In addition, there were no differences between the groups in reoperation rates, even in younger patients (age $<70$ years) (Figure $4, B$ ).

The propensity score-adjusted HRs with a 95\% confidence interval for each event are summarized in Table 4. There were no significant differences in all-cause mortality, bleeding-related mortality, any valve-related events, bleeding events, thromboembolic events, and reoperation rates between the 2 groups. These results were similar even if we analyzed among the patients undergoing first time, isolated AVR $(\mathrm{n}=183)$. However, group $M$ had greater tendency of valve-related mortality than group B (HR 2.0, $P=.06$ ) and significantly greater PVE (HR 4.91, $P=.03$ ). Of note, among the causes of valve-related mortality, the incidences of sudden death tended to be greater in group M than in group B. In fact, the HR of valve-related deaths due to sudden death was $2.39(P=.11)$.

In the Fine-Gray model, the greater risks of Group $M$ in terms of valve-related death and PVE became more significant (HR 2.10, $P=.03$ and HR 4.43, $P=.01$, respectively). Because of the relatively small sample 


\section{Freedom from All-Cause Death}

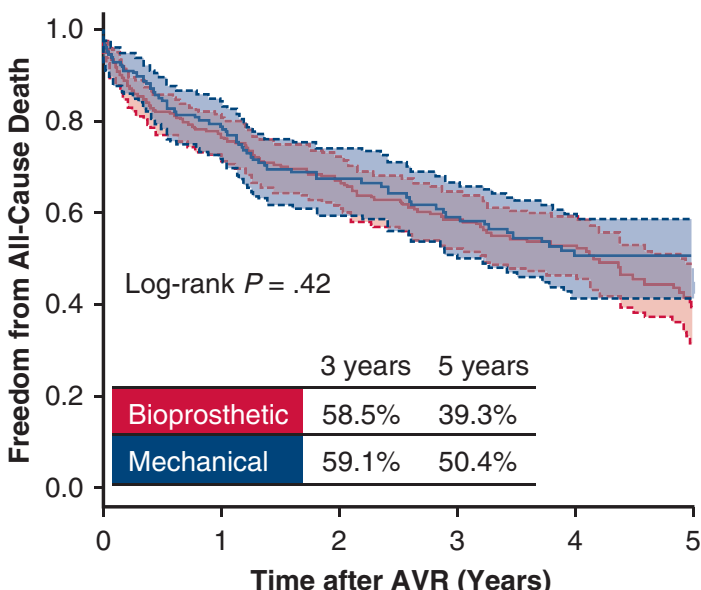

Number at risk

$\begin{array}{lllllll}\text { Bioprosthetic } & 323 & 225 & 145 & 105 & 70 & 37\end{array}$

$\begin{array}{lllllll}\text { Mechanical } & 168 & 122 & 89 & 69 & 47 & 36\end{array}$

A

FIGURE 1. A, Kaplan-Meier curves of freedom from all-cause death. B, Freedom from all-cause death among the patients undergoing first time, isolated aortic valve replacement. Data are unadjusted. $A V R$, Aortic valve replacement.

size, we conducted another sensitivity analysis using the inverse-probability weighting method. The tendency toward greater valve-related mortality and greater incidence of PVE in group $\mathrm{M}$, however, became less
Freedom from All-Cause Death (First time, isolated AVR)

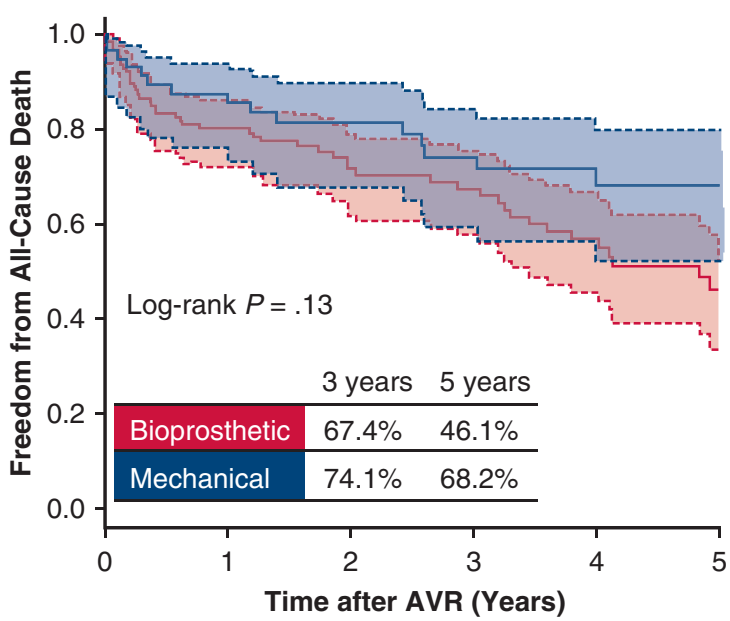

$\begin{array}{lllllll}\text { Bioprosthetic } & 126 & 92 & 58 & 47 & 32 & 18\end{array}$ $\begin{array}{lllllll}\text { Mechanical } & 57 & 43 & 35 & 30 & 21 & 14\end{array}$

B obvious. The details of these additional sensitivity analyses are summarized in Table E1.

Subgroup analyses using propensity score adjustment for late outcomes according to the age at operation are shown in
Freedom from All-Cause Death (Stratified by Age)

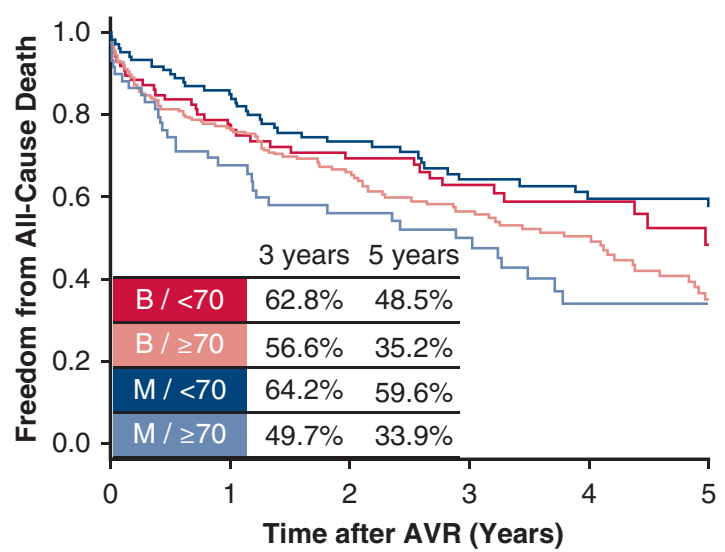

Bioprosthetic $<70 \quad 86$

Bioprosthetic $\geq 70$

Mechanical $<70$

Mechanical $\geq 70$

A

FIGURE 2. A, Kaplan-Meier curves of freedom from all-cause death stratified by age. B, Freedom from valve-related death. Data are unadjusted. AVR, Aortic valve replacement.

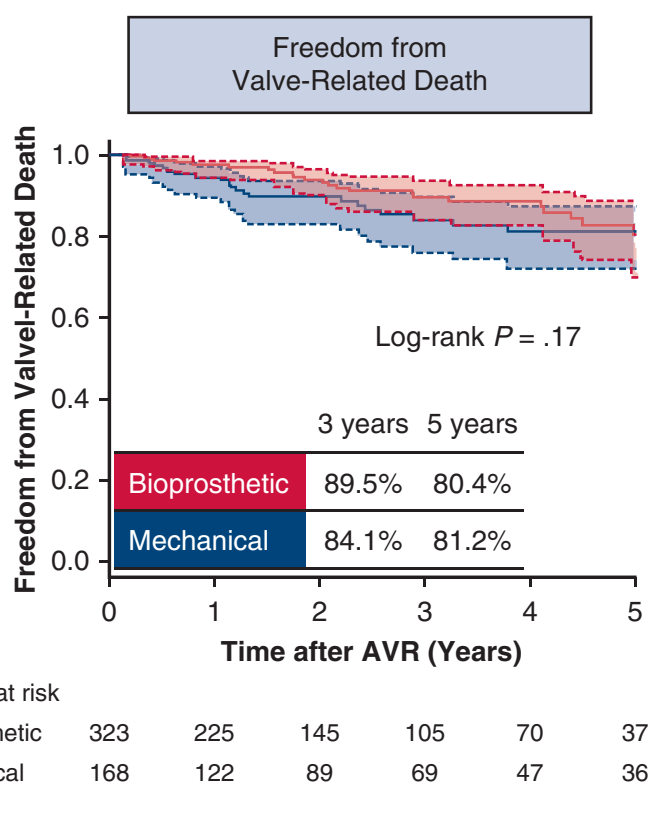

B 
TABLE 3. Late outcomes

\begin{tabular}{|c|c|c|}
\hline & $\begin{array}{c}\text { Group B } \\
(\mathrm{n}=323), \\
\text { bioprosthetic }\end{array}$ & $\begin{array}{c}\text { Group M } \\
(\mathrm{n}=168), \\
\text { mechanical }\end{array}$ \\
\hline All-cause mortality & $107(33.1 \%)$ & $63(37.5 \%)$ \\
\hline Valve-related death & $26(8.0 \%)$ & $23(13.7 \%)$ \\
\hline Bleeding event related & $10(3.1 \%)$ & $8(4.8 \%)$ \\
\hline $\begin{array}{l}\text { Prosthetic valve } \\
\text { endocarditis related }\end{array}$ & $4(1.2 \%)$ & $4(2.4 \%)$ \\
\hline $\begin{array}{l}\text { Thromboembolic event } \\
\text { related }\end{array}$ & $1(0.3 \%)$ & $1(0.6 \%)$ \\
\hline Sudden death & $11(3.4 \%)$ & $10(6.0 \%)$ \\
\hline $\begin{array}{l}\text { Non-valve-related cardiac } \\
\text { death }\end{array}$ & $21(6.5 \%)$ & $10(6.0 \%)$ \\
\hline $\begin{array}{l}\text { Peripheral arterial disease- } \\
\text { related death }\end{array}$ & $10(3.1 \%)$ & $11(6.5 \%)$ \\
\hline Pneumonia & $16(5.0 \%)$ & $3(1.8 \%)$ \\
\hline Infection & $7(2.2 \%)$ & $3(1.8 \%)$ \\
\hline Malignancy & $6(1.9 \%)$ & $2(1.2 \%)$ \\
\hline Gastrointestinal disease & $6(1.9 \%)$ & $2(1.2 \%)$ \\
\hline Others and/or unknown & $15(4.6 \%)$ & $9(5.4 \%)$ \\
\hline \multicolumn{3}{|l|}{ Valve-related event } \\
\hline Bleeding event* & $68(21.1 \%)$ & $42(25.0 \%)$ \\
\hline Thromboembolic event & $11(3.4 \%)$ & $8(4.8 \%)$ \\
\hline $\begin{array}{c}\text { Structural valve } \\
\text { deterioration }\end{array}$ & $6(1.9 \%)$ & 0 \\
\hline $\begin{array}{c}\text { Prosthetic valve } \\
\text { endocarditis }\end{array}$ & $6(1.9 \%)$ & $7(4.2 \%)$ \\
\hline Aortic valve reoperation & $2(0.6 \%)$ & $2(1.2 \%)$ \\
\hline
\end{tabular}

*One patient may have had more than 1 event.

Table 5. The advantages of choosing bioprosthetic valves may be more obvious especially in patients of age 70 years or older. The HR of valve-related mortality in elderly patients of group $\mathrm{M}$ was $2.41(P=.05)$. In addition, the HRs of sudden death, thromboembolic events, and PVE were $3.92(P=.03), 4.21(P=.09)$, and $2.82(P=.23)$, respectively.

The data of serial echocardiographic studies during the follow-up period were collected in 373 patients $(76 \%$ of all surviving patients). The mean duration between the operation and the latest echocardiography was $2.4 \pm 2.0$ years. Among these 373 patients, 249 patients were in group B. There were 5 patients $(2.0 \%$ of 249 patients) who were found to have developed SVD in group $\mathrm{B}$, according to the aforementioned definition, whereas no patients developed SVD in group M.

\section{DISCUSSION}

It is well recognized that patients who are dependent on chronic hemodialysis have a poor prognosis. Among other conditions, they tend to develop premature systemic atherosclerosis, including cardiovascular calcification, which can cause aortic valve disease. It is commonly believed that bioprosthetic valves have compromised durability in hemodialysis patients because hemodialysis accelerates degeneration even during the early postoperative period. ${ }^{5,6}$ In contrast, some authors argue that patients on hemodialysis have an elevated bleeding tendency, and that this tendency is worsened by the chronic anticoagulation that is necessary with mechanical valves. Thus, there is still controversy about the choice of prosthetic valves in hemodialysis patients. To date, there have not been many large-scale studies focusing on the long-term outcomes, including valve-related complications such as bleeding or thromboembolism, in patients on hemodialysis receiving prosthetic valves. ${ }^{8-14}$ In particular, there have not been many studies on the durability of bioprosthetic valves in patients undergoing dialysis.

Although the overall survival in patients undergoing dialysis after AVR in this study seemed better than that in previous studies conducted in the United States, ${ }^{8,9,13}$ the long-term survival was definitely lower than that of nondialysis patient cohorts, ${ }^{8-14}$ and there were no significant differences between mechanical valves $(50.4 \%$ at 5 years) and bioprosthetic valves $(39.3 \%$ at 5 years, $\log$-rank $P=.42$ ). This was also true even after adjusting preoperative characteristics and intraoperative variables with propensity score analyses. Therefore, this study demonstrated that whichever prosthetic valve was chosen, there was no significant difference in overall survival in patients on hemodialysis after AVR.

This study, however, illustrated the better outcomes in patients with bioprosthetic valves compared to patients with mechanical valves in terms of valve-related deaths and incidence of PVE. Figure 2 shows that there were no differences between groups regarding valve-related deaths by unadjusted analysis. However, the HR after adjustment with propensity scores using the Fine-Gray model was estimated at $2.10(P=.03)$ for valve-related mortality with mechanical valves compared to bioprosthetic valves, and this was statistically significant (Table E1). Also, the HR for PVE was $4.43(P=.01)$ using the same method in patients receiving mechanical valves. In general, patients on hemodialysis are thought to have more hemorrhagic events than general patients. ${ }^{19-21}$ Because recipients of mechanical valves must be on chronic anticoagulation therapy with warfarin, we had expected that bleeding events and bleeding-related mortalities would be much greater in group $\mathrm{M}$ than in group B. However, the results did not show any significant differences in this regard between the 2 groups. Despite this, the patients in group $\mathrm{M}$ had a greater tendency to experience sudden deaths and PVE than those in group B. These valve-related events may have contributed to the poor outcomes in group M. Of note, some of the sudden deaths might not have been truly valve-related; therefore, we may have overestimated the influence of mechanical valves on such valve-related mortalities. Our subgroup analyses demonstrated that the 


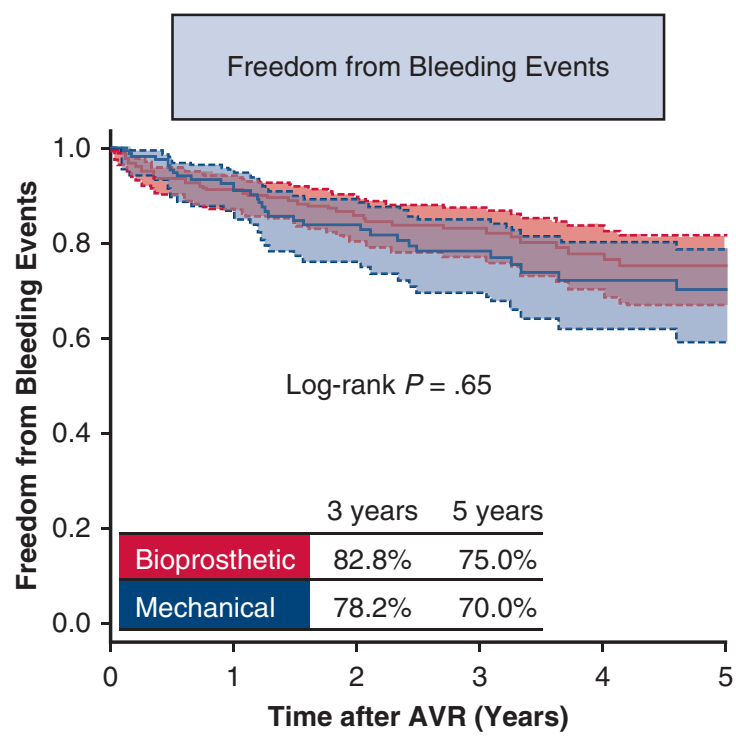

Number at risk

Bioprosthetic 323

Mechanical 168

$\begin{array}{ll}131 & 95 \\ 79 & 59\end{array}$

61

A

FIGURE 3. A, Kaplan-Meier curves of freedom from bleeding events. B, Freedom from thromboembolic events. Data are unadjusted. AVR, Aortic valve replacement.

advantages of choosing bioprosthetic valves are more obvious in elderly patients. Although we could only use one age as a cut-off point (70 years) to conduct meaningful statistical analyses, it was apparent that older patients
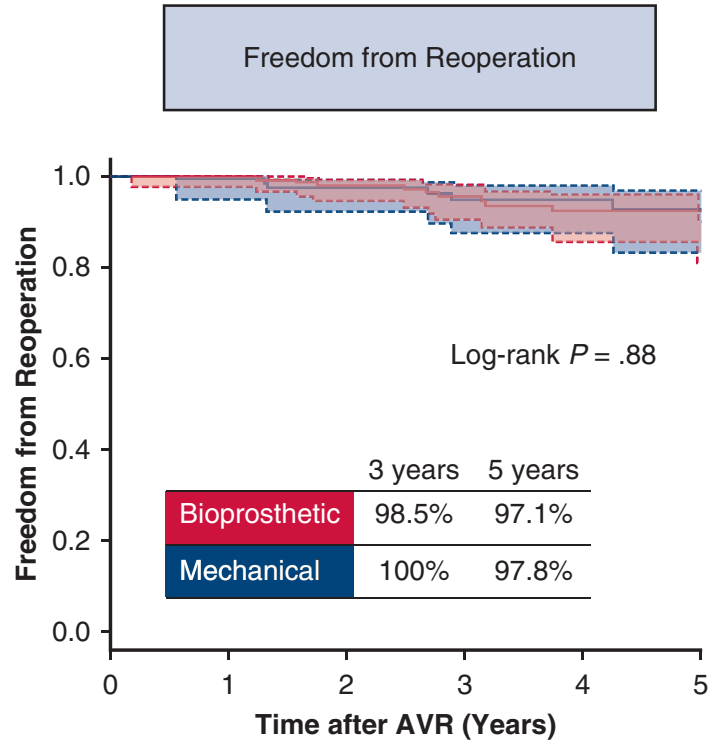

Number at risk

$\begin{array}{llllll}\text { Bioprosthetic } & 323 & 224 & 144 & 104 & 69\end{array}$

$\begin{array}{llllll}\text { Mechanical } & 168 & 122 & 89 & 69 & 47\end{array}$

\section{A}

FIGURE 4. A, Kaplan-Meier curves of freedom from reoperation. B, Freedom from reoperation stratified by age. Data unadjusted. AVR, Aortic valve replacement. would definitely benefit by choosing bioprosthetic valves over mechanical valves.

It has been reported that the linearized ratio of bleeding events after AVR using mechanical valves is approximately

\section{Bioprosthetic $<7086$}

Bioprosthetic $\geq 70237$

Mechanical <70 109

Mechanical $\geq 70 \quad 59$

B
Freedom from Reoperation (Stratified by Age)

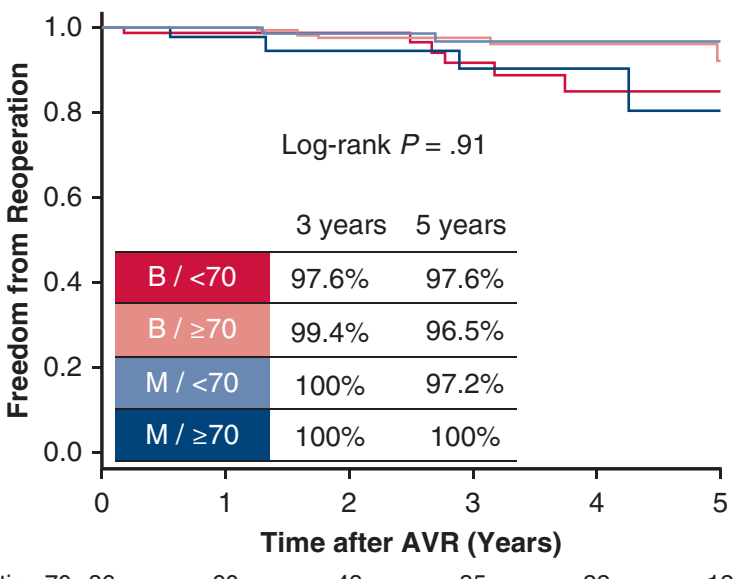

$\begin{array}{lllll}60 & 48 & 35 & 22 & 12\end{array}$

$\begin{array}{lllll}164 & 96 & 69 & 47 & 24\end{array}$

$\begin{array}{lllll}86 & 61 & 47 & 38 & 30\end{array}$

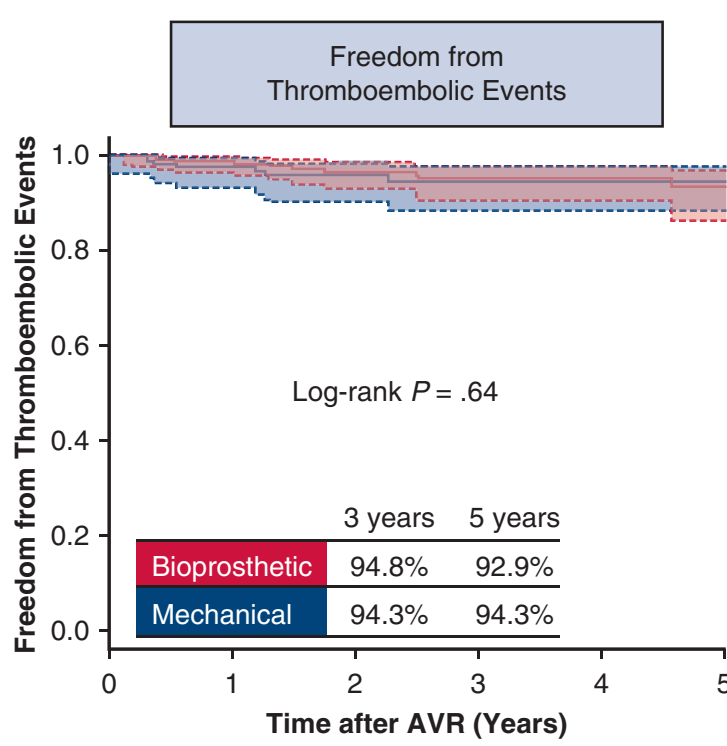

Number at risk

Bioprosthetic 323

Mechanical 168

141

102

70

37

B 
TABLE 4. Propensity score analysis for late outcomes

\begin{tabular}{|c|c|c|c|c|}
\hline & \multicolumn{2}{|c|}{ Cox regression $(n=491)$} & \multicolumn{2}{|c|}{$\begin{array}{l}\text { Comparisons among patients undergoing } \\
\text { first time, isolated AVR }(n=183)\end{array}$} \\
\hline & Hazard ratio $(95 \% \mathrm{CI})^{*}$ & $P$ value & Hazard ratio $(95 \% \mathrm{CI}) *$ & $P$ value \\
\hline All-cause mortality & $1.05(0.73-1.52)$ & .80 & $0.69(0.34-1.39)$ & .30 \\
\hline Non-valve-related cardiac death & $0.73(0.39-1.35)$ & .31 & $0.54(0.16-1.83)$ & .32 \\
\hline Valve-related death & $2.00(0.98-4.06)$ & .06 & $0.90(0.24-3.35)$ & .88 \\
\hline Sudden death & $2.39(0.83-6.87)$ & .11 & $1.82(0.12-27.77)$ & .67 \\
\hline Bleeding-related death & $1.14(0.39-3.40)$ & .81 & $0.40(0.06-2.47)$ & .32 \\
\hline Any valve-related events & $1.30(0.82-2.05)$ & .26 & $1.39(0.64-2.99)$ & .40 \\
\hline Bleeding events & $1.23(0.69-2.17)$ & .48 & $1.24(0.55-2.82)$ & .61 \\
\hline Thromboembolic events & $0.92(0.27-3.10)$ & .89 & Not estimable & - \\
\hline Prosthetic valve endocarditis & $4.91(1.15-20.92)$ & .03 & $3.55(0.25-50.50)$ & .35 \\
\hline Any reoperation & $0.24(0.02-2.33)$ & .22 & $0.22(0.01-4.01)$ & .30 \\
\hline
\end{tabular}

$1 \%$ per year. ${ }^{22-24}$ In the current study, we demonstrated that the bleeding risks were much higher than this average in hemodialysis patients with both mechanical valves and bioprosthetic valves (approximately 5\% per year for bioprosthetic valves, and $6 \%$ per year for mechanical valves). There is sufficient evidence that hemodialysis patients on warfarin therapy have higher hemorrhagic events than those not on warfarin therapy. ${ }^{25-27}$ In the current study, there were 86 patients (51 in group B and 35 in group $\mathrm{M})$ who had bleeding events during the follow-up period. Of these, 31 patients $(61 \%)$ in group B were on anticoagulation therapy with warfarin at the time of the bleeding events. Therefore, it seems clear that anticoagulation therapy increases the risk of bleeding both in mechanical valves and bioprosthetic valves. More interestingly, 84 patients $(36 \%)$ of 236 patients in group B were on anticoagulation therapy with warfarin at the time of the latest follow-up. The indications for warfarin included persistent atrial fibrillation in 18 patients, early postsurgical anticoagulation therapy (within 3 months of surgery) in 12 patients, peripheral arterial diseases in 11 patients, previous history of stroke in 4 patients, prophylaxis for arteriovenous fistula occlusion for hemodialysis in 3 patients, prophylaxis for graft occlusion after CABG in 3 patients, among others.

In addition to anticoagulation therapy itself, Phelan and colleagues ${ }^{28}$ reported that instability of prothrombin timeinternational normalized ratio (PT-INR), which is common in dialysis patients, contributed to frequent hemorrhagic events. In our study, the mean PT-INR at the time of bleeding events was $2.9 \pm 2.0(2.5 \pm 1.8$ in group B, $2.8 \pm 1.9$ in group $\mathrm{M}, P=.18$ ). There were 294 patients whose PT-INR in the follow-up period were available among 406 patients without bleeding events. As a reference, the mean PT-INR during the follow-up period in those 294 patients without bleeding events was $1.7 \pm 0.7(1.5 \pm 0.6$ in

TABLE 5. Subgroup analysis for late outcomes according to age

\begin{tabular}{|c|c|c|c|c|c|}
\hline & \multicolumn{2}{|c|}{ Ages younger than 70 y $(N=195)$} & \multicolumn{2}{|c|}{ Ages 70 y or older $(N=296)$} & \multirow[b]{2}{*}{$P$ for interaction } \\
\hline & Hazard ratio $(95 \% \mathrm{CI})^{*}$ & $P$ & Hazard ratio $(95 \% \mathrm{CI})^{*}$ & $\bar{P}$ & \\
\hline All-cause mortality & $0.87(0.50-1.53)$ & .63 & $1.17(0.72-1.91)$ & .53 & .10 \\
\hline Non-valve-related cardiac death & $0.46(0.18-1.17)$ & .10 & $1.01(0.46-2.20)$ & .98 & .11 \\
\hline Valve-related death & $1.06(0.34-3.29)$ & .93 & $2.41(0.98-5.89)$ & .05 & .08 \\
\hline Sudden death & $0.58(0.10-3.22)$ & .53 & $3.92(1.13-13.55)$ & .03 & .29 \\
\hline Bleeding-related death & $0.96(0.17-5.42)$ & .96 & $0.99(0.23-4.26)$ & .99 & .20 \\
\hline Any valve-related events & $0.96(0.48-1.89)$ & .90 & $1.46(0.81-2.64)$ & .21 & .28 \\
\hline Bleeding events & $1.29(0.55-3.02)$ & .56 & $1.07(0.49-2.35)$ & .87 & .99 \\
\hline Thromboembolic events & $0.21(0.04-1.01)$ & .05 & $4.21(0.82-21.65)$ & .09 & .01 \\
\hline Prosthetic valve endocarditis & Not estimable & - & $2.82(0.52-15.34)$ & .23 & - \\
\hline Any reoperation & $0.65(0.04-11.72)$ & .77 & Not estimable & - & - \\
\hline
\end{tabular}

$C I$, Confidence interval. *Hazard ratios of mechanical valve compared with bioprosthetic valve ( $>1$ indicates bioprosthetic valve is favorable). $\dagger P$ values for comparisons of the hazard ratios for the subgroups (<.05 indicates a significant difference between the 2 hazard ratios). 


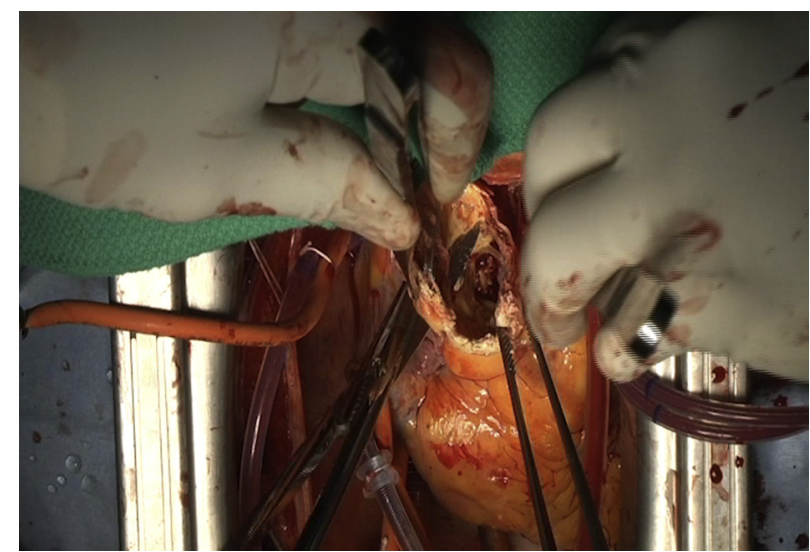

VIDEO 1. One characteristic case that has porcelain aorta that necessitates ascending aorta replacement for aortic valve replacement. Video available at: https://www.jtcvs.org/article/S0022-5223(18)32499-1/fulltext.

group $\mathrm{B}, 2.0 \pm 0.7$ in group $\mathrm{M}, P<.01)$. There were significant differences in PT-INR between the patients who had bleeding events and the patients without bleeding events. Therefore, bleeding events or bleeding-related mortalities may be reduced if we decrease the target PT-INR or even eliminate the use of warfarin in certain dialysis patients receiving bioprosthetic valves.

One of the greatest merits of mechanical valves is greater freedom from reoperation, especially in younger patients. ${ }^{29-31}$ In contrast, reoperation due to SVD in bioprosthetic valves is always a concern. In this study, we found that the incidence of SVD in bioprosthetic valves was only $2.0 \%$ in patients on hemodialysis, and the reoperation rate due to SVD and other reasons among patients on hemodialysis was not particularly high at approximately $2 \%$ to $3 \%$ within 5 years of surgery in both group $\mathrm{M}$ and group $\mathrm{B}$. Even after risk adjustment with propensity score, no differences were found regarding reoperation risk between the 2 groups (Table 4 ). In addition, even in the younger patients ( $<70$ years), there were no differences in reoperation risk between the two groups (Table 5). Because there were only 45 patients (7 patients in group B, and 38 patients in group M) who were younger than 60 years old in this study, we were unfortunately not able to perform statistical analyses using another age cut-off (eg, 60 years), which prevented us from drawing more conclusions regarding the indications for bioprosthetic valves for various ages. However, given the finding that dialysis patients undergoing AVR have a limited life expectancy of approximately $50 \%$ at 5 years postsurgery regardless of the prosthetic valve choice, there seems to be little benefit of choosing mechanical valves overall.

There were several limitations in this study. This was a retrospective and nonrandomized study, and the baseline characteristics of patients in the 2 groups were different.
In particular, we included those patients with endocarditis and/or those undergoing concomitant procedures, which may have had a significant impact on the results. To reduce the impact of these background differences, we adapted propensity scoring for intermediate-term analysis, but it was impossible to exclude all selection biases. Therefore, we conducted sensitivity analyses to include only those patients undergoing first-time, isolated AVR, as summarized in Table 4 . Because of the relatively small sample size, we also used inverse-probability weighting method. Despite these sensitivity analyses, we cannot exclude the possibility of a type II error. In addition, the follow-up duration was very short, and did not appear to be long enough to detect the true reoperation risk due to SVD. Obviously, it will be necessary to conduct a similar study with a longer follow-up period. Furthermore, the echocardiographic data were limited (only available in $76 \%$ of the patients), and the echocardiograms were performed and evaluated at each participating center, not at a core laboratory, which may have yielded various biases. Finally, the overall reoperation rates in both groups were low. This may have been a reflection of some cultural factors whereby Japanese patients were more reluctant to undergo redo operation regardless of indications.

\section{CONCLUSIONS}

There were no significant differences in overall survival between patients on hemodialysis who underwent AVR with bioprosthetic valves and those who underwent AVR with mechanical valves (Video 1).

\section{Conflict of Interest Statement}

Authors have nothing to disclose with regard to commercial support.

We are indebted to the participating hospitals, investigators, and clinical coordinators for their great contributions to data collection. We also thank Mr Christian Rowthorn for his excellent English proofreading.

\section{References}

1. Leon MB, Smith CR, Mack M, Miller DC, Moses JW, Svensson LG, et al; PARTNER Trial Investigators. Transcatheter aortic-valve implantation for aortic stenosis in patients who cannot undergo surgery. N Engl J Med. 2010;363:1597-607.

2. Leon MB, Smith CR, Mack MJ, Makkar RR, Svensson LG, Kodali SK, et al; PARTNER 2 Investigators. Transcatheter or surgical aortic-valve replacement in intermediate-risk patients. N Engl J Med. 2016;374:1609-20.

3. Reardon MJ, Van Mieghem NM, Popma JJ, Kleiman NS, Søndergaard L, Mumtaz M, et al; SURTAVI Investigators. Surgical or transcatheter aorticvalve replacement in intermediate-risk patients. $N$ Engl J Med. 2017;376: $1321-31$.

4. Nishimura RA, Otto CM, Bonow RO, Carabello BA, Erwin JP III, Fleisher LA, et al. 2017 AHA/ACC focused update of the 2014 AHA/ACC guideline for the management of patients with valvular heart disease: a report of the American College of Cardiology/American Heart Association task force on clinical practice guidelines. J Am Coll Cardiol. 2017;70:252-89.

5. Lamberti JJ, Wainer BH, Fisher KA, Karunaratne HB, Al-Sadir J. Calcific stenosis of the porcine heterograft. Ann Thorac Surg. 1979;28:28-32. 
6. Iyer A, Malik P, Prabha R, Kugathasan G, Kuteyi O, Marney L, et al. Early postoperative bioprosthetic valve calcification. Heart Lung Circ. 2013;22:873-4.

7. Bonow RO, Carabello B, de Leon AC, Edmunds LH Jr, Fedderly BJ, Freed MD et al. ACC/AHA guidelines for the management of patients with valvular heart disease. A report of the American College of Cardiology/American Heart Association. Task force on practice guidelines (committee on management of patients with valvular heart disease). J Am Coll Cardiol. 1998;32:1486-588.

8. Herzog CA, Ma JZ, Collins AJ. Long-term survival of dialysis patients in the United States with prosthetic heart valves: should ACC/AHA practice guidelines on valve selection be modified? Circulation. 2002;105:1336-41.

9. Lucke JC, Samy RN, Atkins BZ, Silvestry SC, Douglas JM Jr, Schwab SJ, et al Results of valve replacement with mechanical and biological prostheses in chronic renal dialysis patients. Ann Thorac Surg. 1997;64:129-32.

10. Chan V, Jamieson WR, Fleisher AG, Denmark D, Chan F, Germann E. Valve replacement surgery in end-stage renal failure: mechanical prostheses versus bioprostheses. Ann Thorac Surg. 2006;81:857-62.

11. Umezu K, Saito S, Yamazaki K, Kawai A, Kurosawa H. Cardiac valvular surgery in dialysis patients: comparison of surgical outcome for mechanical versus bioprosthetic valves. Gen Thorac Cardiovasc Surg. 2009;57:197-202.

12. Tanaka K, Tajima K, Takami Y, Okada N, Terazawa S, Usui A, et al. Early and late outcomes of aortic valve replacement in dialysis patients. Ann Thorac Surg. 2010;89:65-70.

13. Williams ML, Bavaria JE, Acker MA, Desai ND, Vallabhajosyula P, Hargrove WC, et al. Valve selection in end-stage renal disease: should it always be biological? Ann Thorac Surg. 2016;102:1531-5.

14. Okada N, Tajima K, Takami Y, Kato W, Fujii K, Hibino M, et al. Valve selection for the aortic position in dialysis patients. Ann Thorac Surg. 2015;99:1524-31.

15. Bonow RO, Carabello BA, Kanu C, de Leon AC Jr, Faxon DP, Freed MD, et al ACC/AHA 2006 guidelines for the management of patients with valvular heart disease: a report of the American College of Cardiology/American Heart Association Task force on practice guidelines (writing committee to revise the 1998 guidelines for the management of patients with valvular heart disease): developed in collaboration with the Society of Cardiovascular Anesthesiologists: endorsed by the Society for Cardiovascular Angiography and Interventions and the Society of Thoracic Surgeons. American College of Cardiology/American Heart Association task force on practice guidelines.; Society of Cardiovascular Anesthesiologists; Society for Cardiovascular Angiography and Interventions; Society of Thoracic Surgeons. Circulation. 2006;114:e84-231.

16. Nishimura RA, Otto CM, Bonow RO, Carabello BA, Erwin JP III, Guyton RA, et al; ACC/AHA Task Force Members. 2014 AHA/ACC guideline for the management of patients with valvular heart disease: a report of the American College of Cardiology/American Heart Association task force on practice guidelines. Circulation. 2014:129:e521-643.

17. Anselmi A, Flecher E, Chabanne C, Ruggieri VG, Langanay T, Corbineau H, et al. Long-term follow-up of bioprosthetic aortic valve replacement in patients aged $\leq 60$ years. J Thorac Cardiovasc Surg. 2017;154:1534-41.
18. Akins CW, Miller DC, Turina MI, Kouchoukos NT, Blackstone EH, Grunkemeier GL, et al; STS; AATS; EACTS. Guidelines for reporting mortality and morbidity after cardiac valve interventions. Ann Thorac Surg. 2008;85: 1490-5.

19. Nakatsu T, Tamura N, Yanagi S, Kyo S, Koshiji T, Sakata R. Hemorrhage as a life-threatening complication after valve replacement in end-stage renal disease patients. Gen Thorac Cardiovasc Surg. 2015;63:386-94.

20. Phan K, Zhao DF, Zhou JJ, Karagaratnam A, Phan S, Yan TD. Bioprosthetic versus mechanical prostheses for valve replacement in end-stage renal disease patients: systematic review and meta-analysis. J Thorac Dis. 2016;8: 769-77.

21. Altarabsheh SE, Deo SV, Dunlay SM, Obeidat YM, Erwin PJ, Rababa'h A, et al. Tissue valves are preferable for patients with end-stage renal disease: an aggregate meta-analysis. J Card Surg. 2016;31:507-14.

22. Minakata K, Tanaka S, Okawa Y, Shimamoto M, Kaneko T, Takahara Y, et al. Long-term outcome of the Carpentier-Edwards pericardial valve in the aortic position in Japanese patients. Circ J. 2014;78:882-9.

23. Minakata K, Tanaka S, Okawa Y, Kaneko T, Okonogi S, Usui A, et al. Twentyyear outcome of aortic valve replacement with St. Jude Medical mechanical valves in Japanese patients. Circ J. 2015;79:2380-8.

24. Anselmi A, Ruggieri VG, Lelong B, Flecher E, Corbineau H, Langanay T, et al. Mid-term durability of the Trifecta bioprosthesis for aortic valve replacement. $J$ Thorac Cardiovasc Surg. 2017;153:21-8.

25. Olesen JB, Lip GY, Kamper AL, Hommel K, Køber L, Lane DA, et al. Stroke and bleeding in atrial fibrillation with chronic kidney disease. N Engl J Med. 2012; 367:625-35.

26. Dahal K, Kunwar S, Rijal J, Schulman P, Lee J. Stroke, major bleeding, and mortality outcomes in warfarin users with atrial fibrillation and chronic kidney disease: a meta-analysis of observational studies. Chest. 2016;149:951-9.

27. Yang F, Chou D, Schweitzer P, Hanon S. Warfarin in haemodialysis patients with atrial fibrillation: what benefit? Europace. 2010;12:1666-72.

28. Phelan PJ, O’Kelly P, Holian J, Walshe JJ, Delany C, Slaby J, et al. Warfarin use in hemodialysis patients: what is the risk? Clin Nephrol. 2011:75:204-11.

29. Furukawa H, Tanemoto K. Current status and future perspectives of prosthetic valve selection for aortic valve replacement. Gen Thorac Cardiovasc Surg. 2014;62:19-23.

30. Zhao DF, Seco M, Wu JJ, Edelman JB, Wilson MK, Vallely MP, et al. Mechanical versus bioprosthetic aortic valve replacement in middle-aged adults: a systematic review and meta-analysis. Ann Thorac Surg. 2016;102:315-27.

31. Minakata K, Tanaka S, Tamura N, Yanagi S, Ohkawa Y, Okonogi S, et al. Comparison of the long-term outcomes of mechanical and bioprosthetic aortic valves-a propensity score analysis. Circ J. 2017;81:1198-206.

Key Words: hemodialysis, end-stage renal disease, prosthetic valve, durability, aortic valve 


\section{APPENDIX}

*PROGRESS-Kyoto includes the following investigators:

Junichiro Nishizawa, $\mathrm{MD}, \mathrm{PhD},{ }^{\mathrm{c}}$ Nobuhisa Ohno, MD, $\mathrm{PhD},{ }^{\mathrm{d}}$ Jiro Esaki, MD, PhD, ${ }^{\mathrm{e}}$ Koji Ueyama, MD, PhD, ${ }^{\mathrm{f}}$ Tadaaki Koyama, MD, PhD, ${ }^{\mathrm{g}}$ Michiya Hanyu, MD, PhD, ${ }^{\mathrm{h}}$ Nobushige Tamura, MD, PhD, ${ }^{\mathrm{i}}$ Tatsuhiko Komiya, MD, $\mathrm{PhD},{ }^{\mathrm{j}}$ Yuhei Saito, MD, PhD, ${ }^{\mathrm{k}}$ Naoki Kanemitsu, MD, $\mathrm{PhD},{ }^{1}$ Yoshiharu Soga, MD, PhD,${ }^{\mathrm{m}}$ Kotaro Shiraga, MD, ${ }^{\mathrm{n}}$ Shogo Nakayama, MD, PhD, ${ }^{\circ}$ Michihito Nonaka, MD, $\mathrm{PhD},{ }^{\mathrm{p}}$ Genichi Sakaguchi, $\mathrm{MD}, \quad \mathrm{PhD},{ }^{\mathrm{q}}$ Kazunobu Nishimura, $\mathrm{MD}, \mathrm{PhD},{ }^{\mathrm{q}}$ and Kazuo Yamanaka, $\mathrm{MD}, \mathrm{PhD}^{\mathrm{r}}$

From the ${ }^{\mathrm{c}}$ Department of Cardiovascular Surgery, Hamamatsu Rosai Hospital, Hamamatsu; ${ }^{\mathrm{d}}$ Department of Cardiovascular Surgery, Hyogo Prefectural Amagasaki General Medical Center, Amagasaki; ${ }^{\mathrm{e} D e p a r t m e n t}$ of Cardiovascular Surgery, Japanese Red-Cross Otsu Hospital, Otsu; ${ }^{\mathrm{f}}$ Department of Cardiovascular Surgery, Kitano Hospital, Osaka; ${ }^{\mathrm{g}}$ Department of Cardiovascular
Surgery, Kobe City Medical Center General Hospital, Kobe; ${ }^{\text {h}}$ Department of Cardiac Surgery, Kokura Memorial Hospital, Kitakyushu; ${ }^{\mathrm{i}}$ Department of Cardiovascular Surgery, Kumamoto Chuo Hospital, Kumamoto; ${ }^{j}$ Department of Cardiovascular Surgery, Kurashiki Central Hospital, Kurashiki; ${ }^{k}$ Department of Cardiovascular Surgery, Matsue Red-Cross Hospital, Matsue; ${ }^{1}$ Department of Cardiovascular Surgery, Mitsubishi Kyoto Hospital, Kyoto; ${ }^{\mathrm{m}}$ Division of Cardiovascular Surgery, Nagahama City Hospital, Nagahama; ${ }^{\mathrm{n}}$ Department of Cardiovascular Surgery, National Hospital Organization Kyoto Medical Center, Kyoto; ${ }^{\circ}$ Department of Cardiovascular Surgery, Osaka Red-Cross Hospital, Osaka; ${ }^{\mathrm{p}}$ Department of Cardiovascular Surgery, Shiga Medical Center for Adults, Moriyama, Shiga; ${ }^{\mathrm{q}}$ Department of Cardiovascular Surgery, Takamatsu Red-Cross Hospital, Takamatsu; and ${ }^{\mathrm{r}}$ Department of Cardiovascular Surgery, Tenri Hospital, Tenri, Japan. 


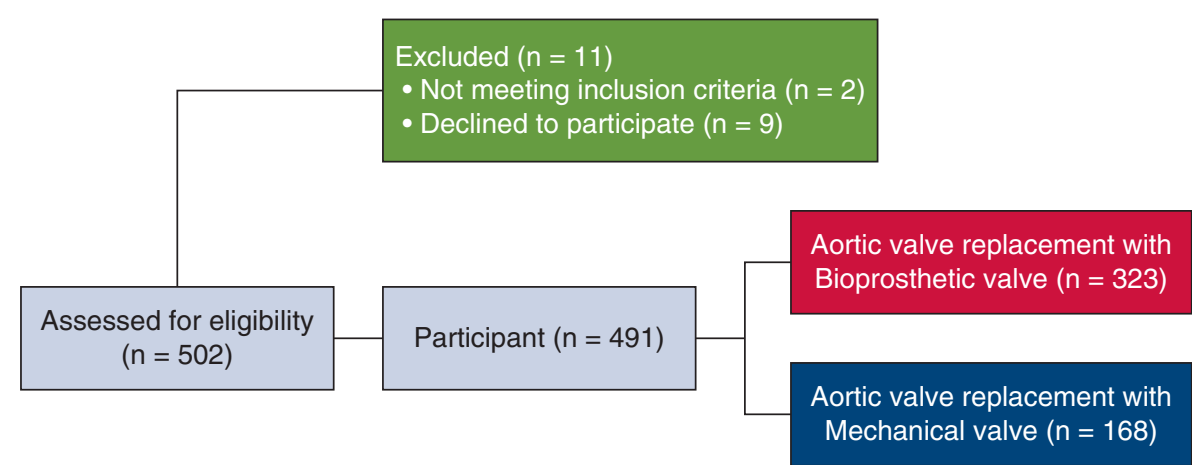

FIGURE E1. Flowchart of patient selection of the study.

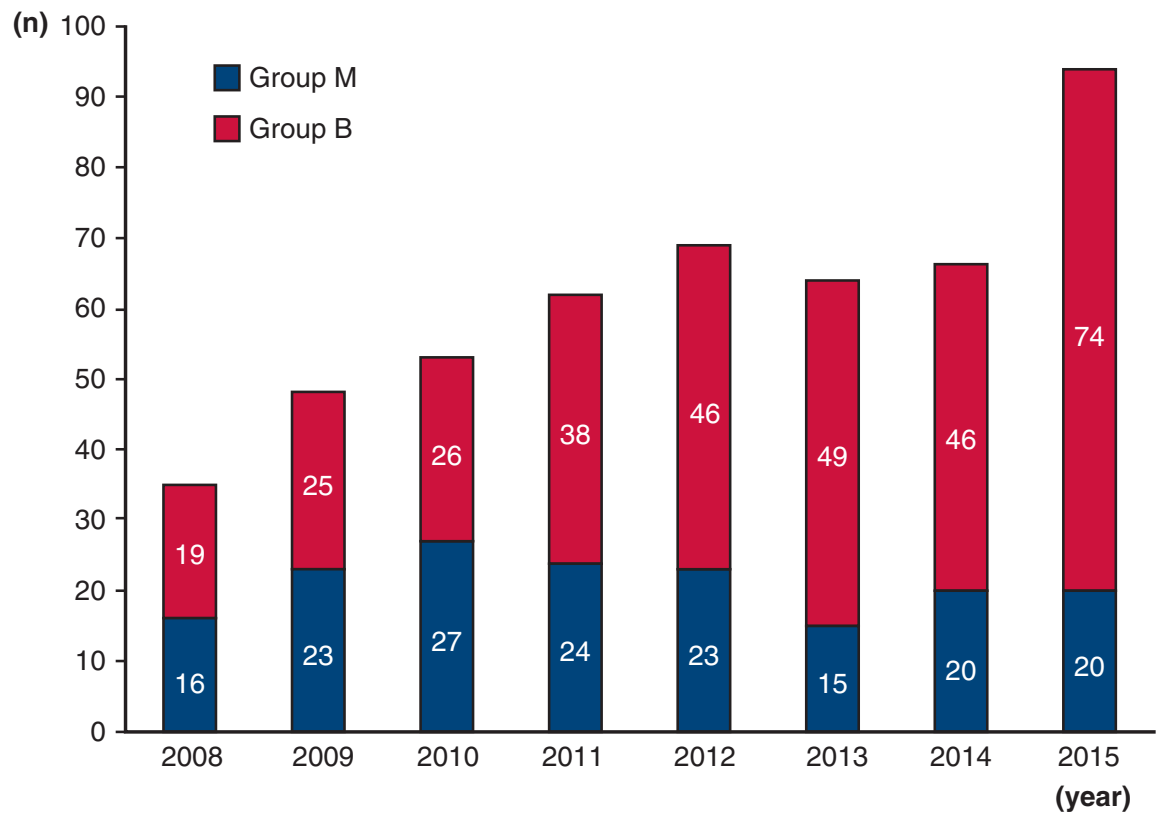

FIGURE E2. Yearly proportion of prosthetic valve choice. 


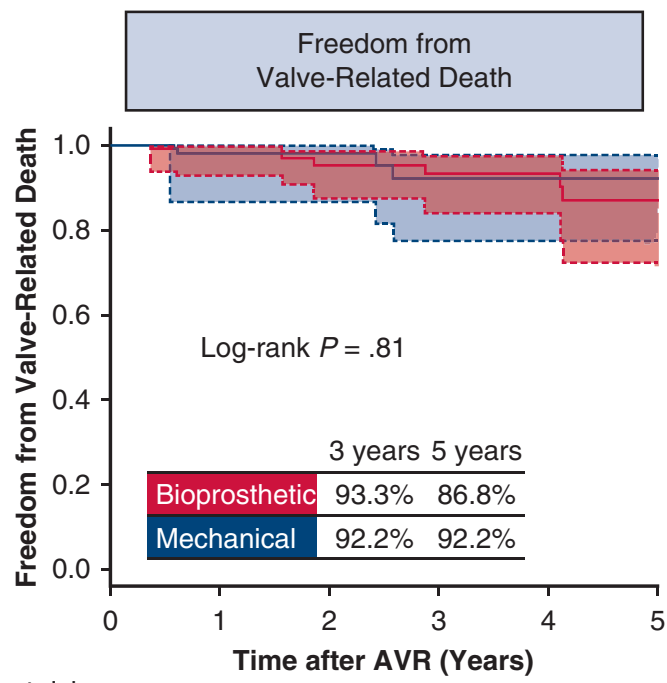

Number at risk

$\begin{array}{lllllll}\text { Bioprosthetic } & 126 & 92 & 58 & 47 & 32 & 18\end{array}$

$\begin{array}{lllllll}\text { Mechanical } & 57 & 43 & 35 & 30 & 21 & 14\end{array}$

FIGURE E3. Kaplan-Meier curves of freedom from valve-related death among the 183 patients undergoing first-time, isolated aortic valve replacement. Data are unadjusted. AVR, Aortic valve replacement.

TABLE E1. Sensitivity analyses for late outcomes (propensity score adjusted) using the Fine-Gray model and inverse-probability weighting method

\begin{tabular}{|c|c|c|c|c|}
\hline & \multicolumn{2}{|c|}{ Inverse-probability weighted Cox regression $(n=491)$} & \multicolumn{2}{|c|}{ Fine-Gray Model $(n=491)$} \\
\hline & Hazard ratio $(95 \% \mathrm{CI}) *$ & $P$ & $\overline{\text { Hazard ratio }(95 \% \mathrm{CI}) \dagger}$ & $P$ value \\
\hline All-cause mortality & $0.90(0.44-1.85)$ & .78 & - & - \\
\hline Non-valve-related cardiac death & $0.79(0.26-2.41)$ & .68 & $0.72(0.36-1.46)$ & .37 \\
\hline Valve-related death & $1.85(0.72-4.76)$ & .20 & $2.10(1.06-4.19)$ & .03 \\
\hline Sudden death & $1.80(0.48-6.74)$ & .38 & $2.58(0.90-7.40)$ & .08 \\
\hline Bleeding-related death & $1.44(0.34-6.06)$ & .62 & $1.14(0.43-3.00)$ & .79 \\
\hline Any valve-related events & $1.01(0.49-2.09)$ & .97 & $1.33(0.84-2.12)$ & .22 \\
\hline Bleeding events & $0.97(0.42-2.20)$ & .94 & $1.22(0.72-2.09)$ & .46 \\
\hline Thromboembolic events & $1.34(0.39-4.66)$ & .64 & $0.94(0.23-3.92)$ & .94 \\
\hline Prosthetic valve endocarditis & $2.37(0.69-8.15)$ & .17 & $4.43(1.50-13.03)$ & .01 \\
\hline Any reoperation & $0.41(0.07-2.56)$ & .34 & $0.30(0.05-2.02)$ & .22 \\
\hline
\end{tabular}

$C I$, Confidence interval. *Hazard ratios of mechanical valve compared with bioprosthetic valve ( $>1$ indicates bioprosthetic valve is favorable). $\dagger$ Subdistribution hazard ratios adjusted for competing risks due to death of mechanical valve compared with bioprosthesis valve ( $>1$ indicates bioprosthesis is favorable). 